\title{
Spiral Computed Tomography Based Maxillary Sinus Imaging in Relation to Tooth Loss, Implant Placement and Potential Grafting Procedure
}

\author{
Maryam Shahbazian', Dong Xue ${ }^{2}$, Yuqian $\mathrm{Hu}^{2}$, Johan van Cleynenbreuge ${ }^{+, 1}$, Reinhilde Jacobs ${ }^{1}$ \\ ${ }^{1}$ Oral Imaging Center, Department of Dentistry, Oral Pathology and Maxillofacial Surgery, Faculty of Medicine, Catholic \\ University of Leuven, Leuven, Belgium \\ ${ }^{2}$ Yu Qian Dental Clinic, DanDong, PR China
}

\author{
Corresponding Author: \\ Reinhilde Jacobs \\ Oral Imaging Center, Faculty of Medicine, \\ Katholieke Universiteit Leuven \\ Kapucijnenvoer 7 \\ BE-3000, Leuven \\ Belgium \\ E-mail: Reinhilde.Jacobs@med.kuleuven.be
}

\begin{abstract}
Objectives: The purpose of the present study was to explore the maxillary sinus anatomy, its variations and volume in patients with a need for maxillary implant placement.

Materials and Methods: Maxillary sinus data of 101 consecutive patients who underwent spiral computed tomography (CT) scans for preoperative implant planning in the maxilla at the Department of Periodontology, University Hospital, KULeuven were retrospectively evaluated. The alveolar bone height was measured on serial cross-sectional images between alveolar crest and sinus floor, parallel to the tooth axis. In order to describe the size of the maxillary sinus anteroposterior (AP) and mediolateral (ML) diameters of the sinus were measured.

Results: The results indicated that the alveolar bone height was significantly higher in the premolar regions in comparison to the molar region $(n=46, P<0.01)$. The age showed negative relation to bone dimension $(r=-0.32, P=0.04)$.

Anterior and posterior border of the maxillary sinuses were mostly located in the first premolar (49\%) and second molar (84\%) regions, respectively. Maxillary sinus septa were indentified in 47\% of the maxillary antra. Almost 2/3 (66\%) of the patients showed major ( $>4 \mathrm{~mm}$ ) mucosal thickening mostly at the level of the sinus floor. The present sample did not allow revealing any significant difference $(\mathrm{P}>0.05)$ in maxillary sinus dimensions for partially dentate and edentulous subjects.

Conclusions: Cross-sectional imaging can be used in order to obtain more accurate information on the morphology, variation, and the amount of maxillary bone adjacent to the maxillary sinus.
\end{abstract}

Keywords: tooth root; alveolar bone atrophy; dental implant; maxillary sinus; computed tomography, spiral; teeth.

Accepted for publication: 9 December 2009

To cite this article:

Shahbazian M, Xue D, Hu Y, Cleynenbreuge J, Jacobs R. Spiral Computed Tomography Based Maxillary Sinus Imaging in Relation to Tooth Loss, Implant Placement and Potential Grafting Procedure

J Oral Maxillofac Res 2010 (Jan-Mar);1(1):e7

URL: http://www.ejomr.org/JOMR/archives/2010/1/e7/e7ht.pdf

doi:10.5037/jomr.2010.1107 


\section{INTRODUCTION}

The use of oral implants for the treatment of partially as well as totally edentulous patients has increased incredibly. Nowadays more imaging techniques have become available for the preoperative planning of oral implant surgery, each with their own strength and weaknesses and specific indications [1]. In many cases, the use of three-dimensional imaging may be beneficial as compared to two-dimensional imaging and overcome its limitations $[\underline{2}, \underline{3}]$.

In particular, placement of dental implants in the posterior maxilla can be jeopardized by several factors. The predominant problem is undoubtedly the lack of bone quantity. Considering that maxillary sinus floor elevation surgery may be indicated when dealing with cases of insufficient bone below the maxillary sinus, a closer look to its anatomical variations seems a necessity. It should be considered that the maxillary sinus has a close relation to the roots of the maxillary molars and bicuspids. Normally tooth apices and the maxillary floor are separated by cortical bone, but some teeth (such as the first and second maxillary molar) are only separated from the maxillary sinus floor by a thin mucosal layer [4-6]. The volume of the maxillary sinus has a natural tendency to increase during life. Tooth loss in the posterior maxilla can result a rapid alveolar bone resorption caused by inherent bone remodelling of the alveolar bone. In addition, the maxillary sinus extends further by osteoclast activity in the Schneiderian membrane, causing pneumatisation of the sinus by resorbing bone within a few months $[7,8]$.

Because of the intimate relationship between teeth and maxillary sinus, periapical infections might result in reactive mucosal response within the sinus. Maxillary sinus mucosal thickening is twice as common in patients with dental disease as in the general population [9] and odontogenic sinusitis accounts for approximately $10 \%$ to $12 \%$ of all cases of maxillary sinusitis [6]. Failure to recognize the tooth as a cause of sinus disease can result in incomplete or inadequate therapy and mismanagement of these conditions $[\underline{5}, 9]$.

Although surgical interventions involving the maxillary sinus are increasing, the presurgical planning continues using two-dimensional radiographs for maxillary sinus visualization [10-12]. Considering the anatomical variability related to the surgical site, including the maxillary sinus floor and its intimate contact with the maxillary posterior teeth, observations on the three-dimensional structure are most useful in relation to implant surgery and sinus grafting. Yet the literature on this is rather scarce [4]. Therefore, the aim of this study was to explore the maxillary sinus anatomy using spiral computed tomography in order to obtain more accurate information on the morphology, variation, volume and the amount of maxillary bone adjacent to the sinus.

\section{MATERIAL AND METHODS}

Maxillary sinus computed tomography (CT) data of 101 consecutive patients (edentulous and partially dentate) visiting the department of Periodontology, University Hospital, Catholic University of Leuven, Leuven, Belgium were assessed. While 30 patients (14 males, 16 females; aged 20 to 70 years; mean age $=53.8$ years) were edentulous, 71 were partially edentulous (36 males, 35 females; aged 22 to 80 years; mean age $=52.8$ years). They all gave informed consent to undergo maxillary spiral CT scans as part of the clinical procedure for preoperative planning of implant placement in the maxilla.

Spiral CT was carried out by Somaton Plus R CT scanner (Siemens, Erlangen, Germany) at 120 $\mathrm{kV}, 165 \mathrm{mAs}, 500 \mu \mathrm{m}$ reconstructed voxel size at the Department of Radiology University Hospital, Catholic University of Leuven, Leuven, Belgium. The axial plan was positioned parallel to the hard palate of the maxilla. For the computer-assisted navigation system, a dual scanning procedure was used to allow the prosthetic model to be visualized together with the jaw bone reconstruction. The latter included a scanning of the patient with the scan prosthesis and some radio-opaque markers included, followed by another scanning of the prosthesis only. This set-up allowed identification of the respective edentulous sites with standardized linear measurements of the bone height at the level of each tooth site.

\section{Dimensional measurements}

Below is an overview of the measurement of the patient's spiral CT scans employed for exploration of the maxillary sinus anatomy, its variation and volume.

1. The minimum and maximum alveolar bone height was measured on cross-sectional images between alveolar crest and maxillary sinus floor (Figure 1), as measured parallel to each tooth or scan prosthesis axis. 2. The size of the maxillary sinus according to anteroposterior (AP) and mediolateral (ML) diameters of the sinus was measured (Figure 2) at 5, 10, 15 and 20 $\mathrm{mm}$ above the most apical level of the maxillary sinus floor.

3. Mucosal thickening of the maxillary sinus was defined as the existence of soft tissue structures thickness $>4 \mathrm{~mm}$. 


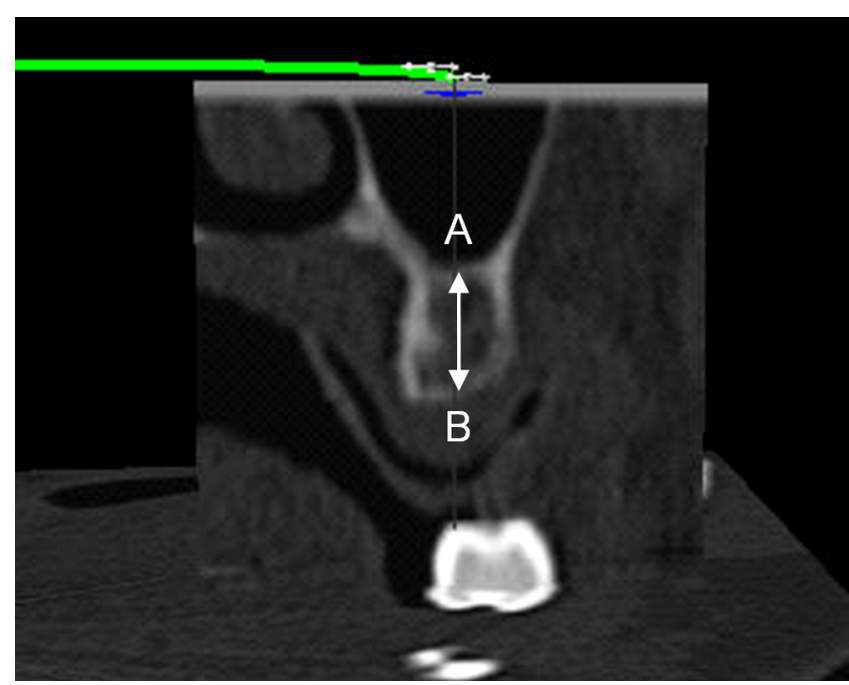

Figure 1. Cross-sectional image showing measurement of the alveolar bone height below the sinus at the level of the respective (prosthetic) tooth: the distance between the floor of the maxillary sinus (A) and the alveolar crest (B) was considered to be the alveolar bone height below the maxillary sinus floor.

All measures were done using an accurate measuring tool (with an accuracy to the nearest $=0.1$ $\mathrm{mm}$ ) in the viewing software, by using a diagnostic screen (SGI, Fremont, CA, USA). Measures were performed by two observers D.X. and R.J. (1 oral surgeon and 1 dentomaxillofacial radiologist), and $10 \%$ of the measures was repeated to determine the intra- and intersubject variability. The latter yielded a non-significant variability, with a coefficient of variation below $4 \%$ for both intra- and inter-observer measurements.

\section{Morphologic assessments}

The maxillary sinus was also assessed morphologically, by determining the anterior and posterior extends of the maxillary sinus, in relation to the respective teeth or estimated tooth sites, in case of edentulism. This morphological rating was done on axial, sagital and panoramic slices. At the same time the occurrence of sinus septa was noted on axial and sagital slices. This morphological assessment allowed a general scoring on sinus morphology and the occurrence of any asymmetry (which was also confirmed dimensionally, see previous paragraph).

Morphologic measures were done by the same observers (D.X., R.J.) using the same viewing software and the same diagnostic screen (SGI, Fremont, CA, USA).

\section{Data and Statistical analysis}

Above mentioned data were pooled and averaged for further analysis. Descriptive variables included dental status, the number of septa in the maxillary sinus,

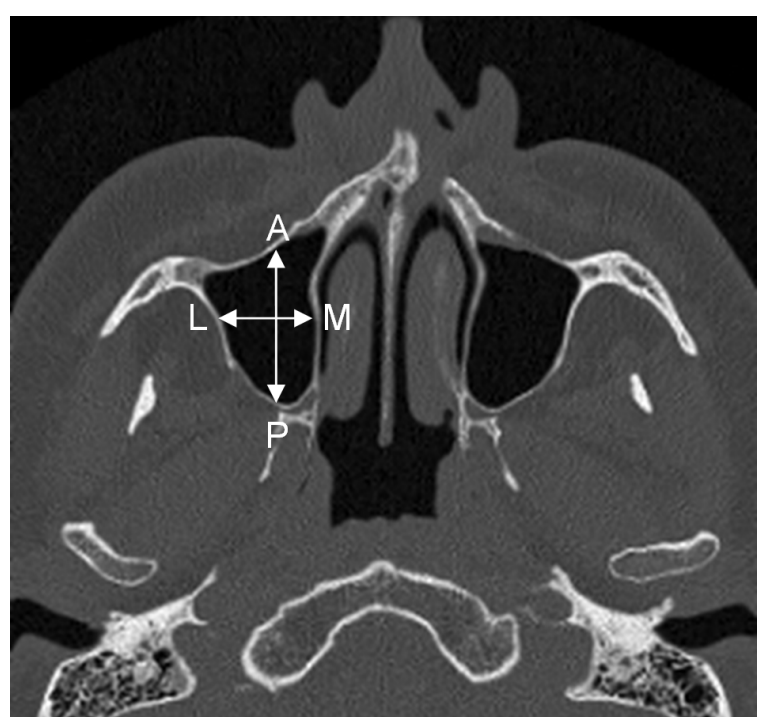

Figure 2. Serial axial slice showing measurement of the maxillary sinus dimensions: anteroposterior (AP) and mediolateral (ML) measures were performed at 5, 10, 15 and $20 \mathrm{~mm}$ above the most apical level of the maxillary sinus floor.

the respective location and morphologic variation of the sinus. Statistical analysis was performed using the statistical package of NCSS 2000 (Kaysville, Utah, USA). Data were tested for normality which yielded a skewed data set necessitating non-parametric analysis. Descriptive statistics were used for all linear measurements. Afterwards, Wilcoxon matched pairs test was applied for non-parametric analysis. The Pearson rank correlation was used to test the correlation between age and alveolar bone height. Differences were considered as statistically significant when P-values were less than 0.05 .

\section{RESULTS}

\section{Dimensional measurements}

\section{Alveolar bone height under the maxillary sinus floor}

The outcome of the linear bone measurement in edentulous and partially dentate patients is shown in Tables 1 and 2. No significant differences were observed between both groups $(\mathrm{P}>0.05)$. Further analysis indicated that the mean values of the alveolar bone height were significantly higher in the premolar region than in the molar region $(\mathrm{n}=46 ; \mathrm{P}<0.01)$. Besides, age showed a negative relation to bone dimension $(\mathrm{r}=-0.32, \mathrm{P}=0.04)$

\section{Size of the maxillary sinus}

In order to describe the size of the maxillary sinus, AP (length) and ML (width) dimensions were determined and the mean values in partially dentate and edentulous patients are shown in Table 3. The AP and ML 
dimensions of the maxillary sinus were in the range of 38 (SD 5.2) $\mathrm{mm}$ and 23.5 (SD 5.1) $\mathrm{mm}$ respectively. There was no significant difference between both groups in AP and ML measurements $(\mathrm{P}>0.05)$.

\section{Location of the mucosal thickening in the maxillary sinus}

The data also showed that almost $2 / 3$ of patients $(66 \%)$ showed major $(>4 \mathrm{~mm})$ mucosal thickening, mostly located on the maxillary sinus floor, with a complete absence of swelling only found in $11 \%$ of the cases. Furthermore, 11 cases of mucosal retention cysts in the left $(n=5)$ and right $(n=6)$ side of the maxillary sinus were observed.

\section{Morphologic assessments}

\section{The extension of the maxillary sinus}

According to the present study, the anterior borders of the maxillary sinus were located mostly at the level of the premolar region with first premolar being $44.7 \%$ and $52.6 \%$ for right and left sides respectively. Meanwhile 78.8\% right sinus and $89.5 \%$ left sinus extended distally to the second molar region (Table 4).

\section{Symmetry of maxillary sinus}

The shape and size of the maxillary sinus could alter throughout the life. In this study half of the patients $(50 \%)$ showed a somewhat symmetric morphology. One third (33\%) of the patients had some differences at several levels while the remaining patients $(17 \%)$ showed a predominant asymmetric morphology.

\section{Septa in maxillary sinus}

The prevalence of one or more septa in overall study population was $47 \%$. No correlation was found between the number of septa and the sinus morphology. However,
Table 1. Minimum alveolar bony height ${ }^{\mathrm{a}}$ in edentulous and partially dentate patient as measured in parallel to respective (prosthetic) tooth axis

\begin{tabular}{|c|c|c|c|c|c|c|c|}
\hline \multirow{2}{*}{ 气̊. } & \multirow{2}{*}{ Statistics } & \multicolumn{6}{|c|}{ Tooth position and value of minimum bony height } \\
\hline & & 15 & 16 & 17 & 25 & 26 & 27 \\
\hline \multirow{3}{*}{ 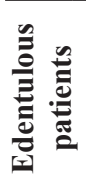 } & $\begin{array}{l}\text { Mean } \\
\text { (SD) }\end{array}$ & $9.2(4)$ & $7.3(4.6)$ & $6.7(4.3)$ & $8(5.3)$ & $4.9(2.8)$ & $5.1(3.5)$ \\
\hline & Range & $5-16.7$ & $1.1-17.9$ & $1.1-14.5$ & $2.2-20.5$ & $1.3-9.0$ & $1.1-11.7$ \\
\hline & $\mathrm{N}$ & 14 & 15 & 13 & 13 & 15 & 15 \\
\hline \multirow{3}{*}{ 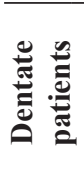 } & $\begin{array}{l}\text { Mean } \\
\text { (SD) }\end{array}$ & $9.5(5.1)$ & $6.2(3.5)$ & $5.7(3.2)$ & $10(5.1)$ & $6.3(3.9)$ & $6(3.3)$ \\
\hline & Range & $2.6-22.4$ & $1.3-12.1$ & $1.1-12$ & $2.3-18.2$ & $1.4-12.5$ & $1.3-12.4$ \\
\hline & $\mathrm{N}$ & 32 & 31 & 27 & 27 & 28 & 26 \\
\hline \multicolumn{2}{|c|}{$\mathbf{P}^{\mathbf{b}}$ value } & $0.95^{\mathrm{c}}$ & $0.57^{\mathrm{c}}$ & $0.57^{\mathrm{c}}$ & $0.17^{\mathrm{c}}$ & $0.31^{\mathrm{c}}$ & $0.40^{\mathrm{c}}$ \\
\hline
\end{tabular}

${ }^{a}$ Alveolar bony height values in $\mathrm{mm}$.

${ }^{\mathrm{b}}$ Tested between the dentate and edentulous patients dimensions.

${ }^{\mathrm{c}}$ The mean differences are not significant at $95 \%$ significance level. $\mathrm{SD}=$ standard deviation.

Table 2. Maximum alveolar bony height ${ }^{\mathrm{a}}$ in edentulous and partially dentate patient as measured in parallel to respective (prosthetic) tooth axis

\begin{tabular}{|c|c|c|c|c|c|c|c|}
\hline \multirow[t]{2}{*}{$\mathfrak{E}_{3}$} & \multirow{2}{*}{ Statistics } & \multicolumn{6}{|c|}{ Tooth position and value of maximum bony height } \\
\hline & & 15 & 16 & 17 & 25 & 26 & 27 \\
\hline \multirow{3}{*}{ 总 } & $\begin{array}{c}\text { Mean } \\
\text { (SD) }\end{array}$ & $12.2(3.8)$ & $10.4(4.9)$ & $9.7(4.8)$ & $11.8(4.4)$ & $8.8(4.6)$ & $8.6(4.4)$ \\
\hline & Range & $8.2-19.6$ & $63.2-21.2$ & $1.3-16.9$ & $5.8-20.9$ & $3-17.9$ & $1.9-16.1$ \\
\hline & $\mathrm{N}$ & 14 & 15 & 13 & 13 & 15 & 15 \\
\hline \multirow{3}{*}{ 。气 } & $\begin{array}{c}\text { Mean } \\
\text { (SD) }\end{array}$ & $13.0(4.6)$ & $10.2(4.6)$ & $8.2(3.4)$ & $13.9(4.8)$ & $10.3(4.7)$ & $8.6(3.5)$ \\
\hline & Range & $4.9-21.5$ & $52.6-22.7$ & $2.9-14.9$ & $5-20.2$ & $2.7-19.4$ & $42.8-14.7$ \\
\hline & $\mathrm{N}$ & 32 & 31 & 27 & 27 & 28 & 26 \\
\hline \multicolumn{2}{|c|}{$\mathbf{P}^{\mathrm{b}}$ value } & $0.51^{\mathrm{c}}$ & $0.98^{\mathrm{c}}$ & $0.29^{\mathrm{c}}$ & $0.18^{\mathrm{c}}$ & $0.31^{\mathrm{c}}$ & $0.86^{\mathrm{c}}$ \\
\hline
\end{tabular}

${ }^{a}$ Alveolar bony height values in $\mathrm{mm}$.

${ }^{\mathrm{b}}$ Tested between the dentate and edentulous patients dimensions.

${ }^{\mathrm{c}}$ The mean differences are not significant at $95 \%$ significance level.
Table 3. Anteroposterior (AP) and mediolateral (ML) dimensions ${ }^{\mathrm{a}}$ of the sinus in partially dentate and edentulous patient in right and left side

\begin{tabular}{lccccc}
\hline \multirow{2}{*}{ Sinus } & \multicolumn{2}{c}{$\begin{array}{c}\text { Dentate patients } \\
(\mathbf{n}=\mathbf{7 1})\end{array}$} & \multicolumn{2}{c}{$\begin{array}{c}\text { Edentulous patients } \\
(\mathbf{n}=\mathbf{3 0})\end{array}$} & $\begin{array}{c}\mathbf{P}^{\mathbf{b}} \\
\text { value }\end{array}$ \\
\cline { 2 - 5 } & $\begin{array}{c}\mathbf{A P} \\
\text { dimension }\end{array}$ & $\begin{array}{c}\text { ML } \\
\text { Rimension }\end{array}$ & $\begin{array}{c}\text { AP } \\
\text { dimension }\end{array}$ & $\begin{array}{c}\text { ML } \\
\text { dimension }\end{array}$ \\
\hline Left & $37.4(4.7)$ & $24.8(4.6)$ & $38(5.2)$ & $25.5(5.2)$ & $0.49^{\mathrm{c}}$ \\
\hline
\end{tabular}

${ }^{a}$ Anteroposterior and mediolateral dimensions expressed as mean values (standard deviation) in $\mathrm{mm}$.

${ }^{\mathrm{b}}$ Tested between the dentate and edentulous patients dimensions.

${ }^{\mathrm{c}}$ The mean differences are not significant at 95\% significance level.
Table 4. Patient left and right maxillary sinus anterior and posterior border location in accordance to the tooth position

\begin{tabular}{|c|c|c|c|c|}
\hline \multirow{2}{*}{ 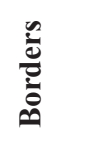 } & \multirow{2}{*}{ Maxillary teeth } & \multicolumn{3}{|c|}{ Maxillary Sinus } \\
\hline & & $\begin{array}{l}\text { Right } \\
(\mathrm{n}[\%])\end{array}$ & $\begin{array}{c}\text { Left } \\
(\mathrm{n}[\%])\end{array}$ & $\begin{array}{l}\text { Pooled } \\
\text { (n [\%]) }\end{array}$ \\
\hline \multirow{4}{*}{ 离 } & Canine & $3(7.9)$ & $2(5.3)$ & $5(6.6)$ \\
\hline & First premolar & $17(44.7)$ & $20(52.6)$ & $37(48.7)$ \\
\hline & Second premolar & $16(42.1)$ & $12(31.6)$ & $28(36.9)$ \\
\hline & First molar & $2(5.3)$ & $4(10.5)$ & $6(7.8)$ \\
\hline \multirow{4}{*}{ 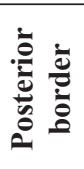 } & Second premolar & $1(2.6)$ & $0(0)$ & $1(1.3)$ \\
\hline & First molar & $3(7.9)$ & $2(5.3)$ & $5(6.6)$ \\
\hline & Second molar & $30(78.8)$ & $34(89.5)$ & $64(84.2)$ \\
\hline & Third molar & $4(10.5)$ & $2(5.3)$ & $6(7.9)$ \\
\hline
\end{tabular}


the statistical analysis between the number of the septum and AP dimension showed that the AP dimension was smaller in patients without septum as compared to patients with various sinus septa, but only in left side $(\mathrm{P}=0.04)$ (Table 5).

\section{DISCUSSION}

Results of the present study demonstrated a considerable difference in mean values of the alveolar bone height for the two groups of patients (edentulous and partially dentate). Extreme differences were observed when contrasting the first molar region in edentulous patients (4.9 [SD 2.8] $\mathrm{mm}$; range $1.3-9 \mathrm{~mm}$ ) to the second premolar region in dentate subjects (13.9 [SD 4.8] $\mathrm{mm}$; range $5-20.2 \mathrm{~mm}$ ). It is striking that after tooth extraction such a drastic difference can exist between posterior maxillae with and without teeth (on average 9 $\mathrm{mm}$ difference). Thus placement of dental implants in these patients requires preprosthetic surgical procedures such as alveolar ridge or sinus floor augmentation with bone grafting.

Although there is a wide range of maxillary sinus dimensions in different studies that may reflect the influential effects like human variability and triggering of pneumatisation [13-17]. Analysis of maxillary sinus by application of high-resolution $\mathrm{CT}$ in this study revealed $\mathrm{AP}$ and ML dimensions of maxillary sinus in the range of 38 (SD 5.2) $\mathrm{mm}$ and 23.5 (SD 5.1) $\mathrm{mm}$ respectively. Although Sharan et al. [18] has reported post extraction maxillary sinus pneumatisation, but in this study there were no registered significant differences between AP and ML dimensions in partially dentate and edentulous patients. Similarly Ariji et al. [19] also found no significant difference in maxillary sinus volume in dentate and edentulous patients of the same age.

Yet, it should be considered that linear measures, as used in the current study, do not fully reflect a threedimensional volume of maxillary sinus.

It is obvious that the use of volumetric measures of the sinus may be more precise and could thus reveal distinct results. Further studies are needed to study the behaviour of the maxillary sinus in conjunction to tooth extraction, implant placement and sinus grafting procedures. In such future studies, the current problem of an unequal sample size (30 edentulous, 71 dentate) should also be dealt with.

Significant mucosal thickening was observed in $66 \%$ of the study group and is presumably related to periapical or periodontal diseases. Others also found that the presence of restorative dentistry and periapical infection can result in focal mucosal thickening in
Table 5. Anteroposterior (AP) ${ }^{\mathrm{a}}$ dimension of the patients' left and right sinus depending on sinus septa presence

\begin{tabular}{lccccc}
\hline \multicolumn{1}{c}{ Sinus } & N & $\begin{array}{c}\text { Sinus without } \\
\text { septum }\end{array}$ & N & $\begin{array}{c}\text { Sinus with } \\
\text { septa }\end{array}$ & $\begin{array}{c}\mathbf{P}^{\mathrm{b}} \\
\text { value }\end{array}$ \\
\hline Right $(\mathrm{n}=98)$ & 56 & $36.9(5)$ & 42 & $38.6(4.5)$ & $0.21^{\mathrm{c}}$ \\
Left $(\mathrm{n}=98)$ & 50 & $35.8(6.1)$ & 48 & $37.9(3.8)$ & $0.04^{\mathrm{d}}$ \\
\hline
\end{tabular}

${ }^{a}$ Anteroposterior dimension expressed as mean values (standard deviation) in $\mathrm{mm}$.

${ }^{\mathrm{b}}$ Tested between AP dimensions of maxillary sinus with and without septa.

${ }^{\mathrm{c}}$ The mean differences are not significant at $95 \%$ significance level.

${ }^{\mathrm{d}}$ The mean differences are significant at $95 \%$ significance level.

the floor of the maxillary sinus $[20,21]$.

The extension of the maxillary sinus is variable in the population. In the present study the anterior border was in the premolar region and posterior border located mostly in second molar region, but in some studies the posterior border of the maxillary sinus in third molar and tuberosity area was reported [14].

In $83 \%$ of patients a symmetric morphology or small differences at some levels in maxillary sinus was shown, while the remaining patients $(17 \%)$ showed a predominant asymmetric morphology. There is not much data concerning the asymmetry of the maxillary sinus. Some studies considered neighbouring cartilages or bony structures as an influencing factor in shape and enlargement of the paranasal sinuses [22].

Mucosal retention cysts in the sinus are mostly found by accident as clinical signs and symptoms are limited and majority of these cysts have spontaneous regression [23]. In the current study the right side showed a slight predominance but because of insufficient quantity of this cyst in our study population we cannot draw a conclusion.

The presence of anatomic variations within the maxillary sinus, such as septa, can increase the risk of sinus membrane perforation during sinus elevation procedures [24]. The prevalence of the septa in our study population was $47 \%$ and AP length was larger in patients that had more than 1 septum as compared to patients without septa. The incidence of antral septa varies from $16 \%$ to $69 \%$ in different studies [ $[19$, 25-28]. This large variation may be related to a wide anatomical variation in the appearance of the maxillary sinus in different study group populations and the ratio of edentulous versus dentate patients can influence the outcome because etiologically, antral septa constitute congenital (primary) and secondary septa formed in edentulous patients $[19,29]$.

It seems obvious that there are lots of variations in the maxillary sinus anatomy and a three-dimensional imaging yields much more information than plain film. 
In this respect, $\mathrm{CT}$ is a valuable imaging modality for three-dimensional evaluations of the anatomical structures but its major drawback remains the inherent costs and the radiation concern. Current low dose CT protocols may however enable low dose imaging of the paranasal sinuses $[\underline{30}, \underline{31}]$. Alternatively, one may nowadays apply cone beam CT imaging as it offers a simple chair side technique, with low radiation burden and reduced costs [32].

\section{CONCLUSIONS}

In the present study, higher mean values in alveolar bone height were observed in the premolar region, while more bone loss occurred in older individuals. Anterior and posterior border of the maxillary sinus were located in the first premolar and second molar respectively.
Most of the patients (83\%) showed symmetric or small differences sinus morphology in both sides, while almost half of the subjects showed sinus septa. Mucosal thickening was seen in $2 / 3(66 \%)$ of the patients mostly in the sinus floor.

\section{ACKNOWLEDGMENTS AND DISCLOSURE STATEMENTS}

We would like to acknowledge the immense amount of work put into the initial project by Professor Johan van Cleynenbreugel, Oral Imaging Center, Faculty of Medicine, Catholic University of Leuven, Leuven, Belgium who passed away during the course of this research.

The authors declare that they have no conflict of interest.

\section{REFERENCES}

1. BouSerhal C, Jacobs R, Quirynen M, van Steenberghe D. Imaging technique selection for the preoperative planning of oral implants: a review of the literature. Clin Implant Dent Relat Res. 2002;4(3):156-72. Review. [Medline: 12516649] [doi: 10.1111/j.1708-8208.2002.tb00167.x]

2. Jacobs R, Adriansens A, Verstreken K, Suetens P, van Steenberghe D. Predictability of a three-dimensional planning system for oral implant surgery. Dentomaxillofac Radiol. 1999 Mar;28(2):105-11. [Medline: 10522199] [doi: 10.1038/sj.dmfr.4600419]

3. Bouquet A, Coudert JL, Bourgeois D, Mazoyer JE, Bossard D. Contribution of reformatted computer tomography and panoramic radiography in the localization of third molar relative to the maxillary sinus. Oral Surg Oral Med Oral Pathol Oral Radiol Endod. 2004: 98; 342-7. [Medline: 15356474] [doi: 10.1016/j.tripleo.2004.02.082]

4. Sharan A, Madjar D. Correlation between maxillary sinus floor topography and related root position of posterior teeth using panoramic and cross-sectional computed tomography imaging. Oral Surg Oral Med Oral Pathol Oral Radiol Endod. 2006 Sep;102(3):375-81. Epub 2006 Jun 8. [Medline: 16920546] [doi: 10.1016/j.tripleo.2005.09.031]

5. Hauman $\mathrm{CH}$, Chandler NP, Tong DC. Endodontic implications of the maxillary sinus: a review. Int Endod J. 2002 Feb;35(2):127-41. Review. [Medline: 11843967] [doi: 10.1046/j.0143-2885.2001.00524.x]

6. Brook I. Sinusitis of odontogenic origin. Otolaryngol Head Neck Surg. 2006 Sep;135(3):349-55. Review. [Medline: 16949963] [doi: 10.1016/j.otohns.2005.10.059]

7. Van den Bergh JP, ten Bruggenkate CM, Krekeler G, Tuinzing DB. Sinus floor elevation and grafting with autogenous iliac crest bone. Clin Oral Impl Res. 1998 Dec;9(6):429-35. [Medline: 11429944] [doi: 10.1034/j.1600-0501.1996.090608.x]

8. Galindo-Moreno P, Avila G, Fernández-Barbero JE, Aguilar M, Sánchez-Fernández E, Cutando A, Wang HL. Evaluation of sinus floor elevation using a composite bone graft mixture. Clin Oral Implants Res. 2007 Jun;18(3):376-82. Epub 2007 Mar 12. [Medline: 17355356] [doi: 10.1111/j.1600-0501.2007.01337.x]

9. Whyte A, Chapeikin G. Opaque maxillary antrum: a pictorial review. Australas Radiol. 2005 Jun;49(3):203-13. [Medline: 15932462] [doi: 10.1111/j.1440-1673.2005.01432.x]

10. Wallace SS, Froum SJ. Effect of maxillary sinus augmentation on the survival of endosseous dental implants. A systematic review. Ann Periodontol. 2003 Dec;8(1):328-43. Review. [Medline: 14971260] [doi: 10.1902/annals.2003.8.1.328] [FREE Full Text]

11. Kaufman E. Maxillary sinus elevation surgery: an overview. J Esthet Restor Dent. 2003;15(5):272-82; discussion 283. Review. [Medline: 14620658] [doi: 10.1111/j.1708-8240.2003.tb00298.x]

12. AlGhamdi AS. Management of combined ridge defect and osteotome sinus floor elevation with simultaneous implant placement--a 36-month follow-up case report. J Oral Implantol. 2009;35(5):225-31. [Medline: 19882818] [doi: 10.1563/AAID-JOI-D-09-00006.1]

13. Ariji Y, Ariji E, Yoshiura K, Kanda S. Computed tomographic indices for maxillary sinus size in comparison with the sinus volume. Dentomaxillofac Radiol. 1996 Jan;25(1):19-24. [Medline: 9084281]

14. Uchida Y, Goto M, Katsuki T, Akiyoshi T. A cadaveric study of maxillary sinus size as an aid in bone grafting of the maxillary sinus floor. J Oral Maxillofac Surg. 1998 Oct;56(10):1158-63. [Medline: 9766541] [doi: $10.1016 / \mathrm{S} 0278-2391(98) 90761-3]$ 
15. Kim HJ, Yoon HR, Kim KD, Kang MK, Kwak HH, Park HD, Han SH, Park CS. Personal-computer-based threedimensional reconstruction and simulation of maxillary sinus. Surg Radiol Anat. 2003 Feb;24(6):393-9. Epub 2003 Jan 21. [Medline: 12652367] [doi: 10.1007/s00276-002-0058-x]

16. Teke HY, Duran S, Canturk N, Canturk G. Determination of gender by measuring the size of the maxillary sinuses in computerized tomography scans. Surg Radiol Anat. 2007 Feb;29(1):9-13. Epub 2006 Dec 14. [Medline: 17171233] [doi: 10.1007/s00276-006-0157-1]

17. Koppe T, Weigel C, Bärenklau M, Kaduk W, Bayerlein T, Gedrange T. Maxillary sinus pneumatization of an adult skull with an untreated bilateral cleft palate. J Craniomaxillofac Surg. 2006 Sep;34 Suppl 2:91-5. [Medline: 17071400] [doi: 10.1016/S1010-5182(06)60020-6]

18. Sharan A, Madjar D. Maxillary sinus pneumatization following extractions: a radiographic study. Int J Oral Maxillofac Implants. 2008 Jan-Feb;23(1):48-56. [Medline: 18416412]

19. Ariji Y, Kuroki T, Moriguchi S, Ariji E, Kanda S. Age changes in the volume of the human maxillary sinus: a study using computed tomography. Dentomaxillofac Radiol. 1994 Aug;23(3):163-8. [Medline: 7835518]

20. Legert KG, Melén I, Heimdahl A, Stierna P. Development and characterization of an animal model of dental sinusitis. Acta Otolaryngol. 2005 Nov;125(11):1195-1202. [Medline: 16353399] [doi: 10.1080/00016480510038149]

21. Connor SE, Chavda SV, Pahor AL. Computed tomography evidence of dental restoration as aetiological factor for maxillary sinusitis. J Laryngol Otol. 2000 Jul;114(7):510-3. [Medline: 10992931] [doi: 10.1258/0022215001906255]

22. Smith TD, Siegel MI, Mooney MP, Burrows AM, Todhunter JS. Formation and enlargement of the paranasal sinuses in normal and cleft lip and palate human fetuses. Cleft Palate Craniofac J. 1997 Nov;34(6):483-9. [Medline: 9431465] [doi: 10.1597/1545-1569(1997)034<0483:FAEOTP >2.3.CO;2]

23. Wang JH, Jang YJ, Lee BJ. Natural course of retention cysts of the maxillary sinus: long-term follow-up results. Laryngoscope. 2007 Feb;117(2):341-4. [Medline: 17277631] [doi: 10.1097/01.mlg.0000250777.52882.7a]

24. Maestre-Ferrín L, Galán-Gil S, Rubio-Serrano M, Peñarrocha-Diago M. Maxillary sinus septa: a systematic review. Med Oral Patol Oral Cir Bucal. 2009 Sep 21. [Epub ahead of print] [Medline: 19767706] [FREE Full Text]

25. Kim MJ, Jung UW, Kim CS, Kim KD, Choi SH, Kim CK, Cho KS. Maxillary sinus septa: prevalence, height, location, and morphology. A reformatted computed tomography scan analysis. J Periodontol. 2006 May;77(5):903-8. [Medline: 16671885] [doi: 10.1902/jop.2006.050247]

26. Velásquez-Plata D, Hovey LR, Peach CC, Alder ME. Maxillary sinus septa: a 3-dimensional computerized tomographic scan analysis. Int J Oral Maxillofac Implants. 2002 Nov-Dec;17(6):854-60. [Medline: 12507246]

27. Shibli JA, Faveri M, Ferrari DS, Melo L, Garcia RV, d'Avila S, Figueiredo LC, Feres M. Prevalence of maxillary sinus septa in 1024 subjects with edentulous upper jaws: a retrospective study. J Oral Implantol. 2007;33(5):293-6. [Medline: 17987862] [doi: 10.1563/1548-1336(2007)33[293:POMSSI]2.0.CO;2]

28. van Zyl AW, van Heerden WF. A retrospective analysis of maxillary sinus septa on reformatted computerised tomography scans. Clin Oral Implants Res. 2009 Aug 30. [Epub ahead of print] [Medline: 19719738] [doi: 10.1111/j.1600-0501.2009.01802.x]

29. Krennmair G, Ulm C, Lugmayr H. Maxillary sinus septa: incidence, morphology and clinical implications. J Craniomaxillofac Surg. 1997 Oct;25(5):261-5. [Medline: 9368861] [doi: 10.1016/S1010-5182(97)80063-7]

30. Brem MH, Zamani AA, Riva R, Zou KH, Rumboldt Z, Hennig FF, Kikinis R, Norbash AM, Schoepf UJ. Multidetector CT of the paranasal sinus: potential for radiation dose reduction. Radiology. 2007 Jun;243(3):847-52. [Medline: 17517938] [FREE Full Text] [doi: 10.1148/radiol.2433050207]

31. Mulkens TH, Broers C, Fieuws S, Termote JL, Bellnick P. Comparison of effective doses for low-dose MDCT and radiographic examination of sinuses in children. AJR Am J Roentgenol. 2005 May;184(5):1611-8. [Medline: 15855126] [FREE Full Text]

32. Liang X, Jacobs R, Hassan B, Li L, Pauwels R, Corpas L, Souza PC, Martens W, Shahbazian M, Alonso A, Lambrichts I. A comparative evaluation of Cone Beam Computed Tomography (CBCT) and Multi-Slice CT (MSCT) Part I. On subjective image quality. Eur J Radiol. 2009 Apr 30. [Epub ahead of print] [Medline: 19410409] [doi: 10.1016/j.ejrad.2009.03.042]

\section{To cite this article:}

Shahbazian M, Xue D, Hu Y, Cleynenbreuge J, Jacobs R. Spiral Computed Tomography Based Maxillary Sinus Imaging in Relation to Tooth Loss, Implant Placement and Potential Grafting Procedure

J Oral Maxillofac Res 2010 (Jan-Mar);1(1):e7

URL: http://www.ejomr.org/JOMR/archives/2010/1/e7/e7ht.pdf

doi: $10.5037 /$ jomr.2010.1107 
Copyright (C) Shahbazian M, Xue D, Hu Y, Cleynenbreuge J, Jacobs R. Accepted for publication in the JOURNAL OF ORAL \& MAXILLOFACIAL RESEARCH (http://www.ejomr.org), 9 December 2009.

This is an open-access article, first published in the JOURNAL OF ORAL \& MAXILLOFACIAL RESEARCH, distributed under the terms of the Creative Commons Attribution-Noncommercial-No Derivative Works 3.0 Unported License, which permits unrestricted non-commercial use, distribution, and reproduction in any medium, provided the original work and is properly cited. The copyright, license information and link to the original publication on (http://www.ejomr.org) must be included. 